\title{
Forever Young! Tintin's Adventures as an Example of Physical Activity and Sport
}

\author{
Alejandro García-Mas ${ }^{1}$, Aurelio Olmedilla ${ }^{2} \mathbb{D}$, Sébastien Laffage-Cosnier ${ }^{3, *}$, Jaume Cruz ${ }^{4,+}$, , Yann Descamps ${ }^{3}$ \\ and Christian Vivier ${ }^{3}$
}

check for updates

Citation: García-Mas, A.; Olmedilla, A.; Laffage-Cosnier, S.; Cruz, J.; Descamps, Y.; Vivier, C. Forever Young! Tintin's Adventures as an Example of Physical Activity and Sport. Sustainability 2021, 13, 2349. https://doi.org/10.3390/su13042349

Academic Editor: Gianpiero Greco

Received: 24 December 2020

Accepted: 17 February 2021

Published: 22 February 2021

Publisher's Note: MDPI stays neutral with regard to jurisdictional claims in published maps and institutional affiliations.

Copyright: (c) 2021 by the authors. Licensee MDPI, Basel, Switzerland. This article is an open access article distributed under the terms and conditions of the Creative Commons Attribution (CC BY) license (https:// creativecommons.org/licenses/by/ $4.0 /)$.
1 GICAFE Research Group, Faculty of Psychology, University of the Balearic Islands, 07122 Palma, Spain; alex.garcia@uib.es

2 Department of Personality, Evaluation and Psychological Treatment, Faculty of Psychology, University of Murcia, 35000 Murcia, Spain; olmedilla@um.es

3 U-Sports Besançon, "Culture, Sport, Health and Society" Research Laboratory, University of Franche-Comté, 25000 Besançon, France; yann.descamps@univ-fcomte.fr (Y.D.); christian.vivier@univ-fcomte.fr (C.V.)

4 Department of Basic, Evolutive and Educational Psychology, Autonomous University of Barcelona, 08071 Barcelona, Spain

* Correspondence: sebastien.laffage-cosnier@univ-fcomte.fr

+ Deceased once this manuscript was submitted, with all authorship credit due.

\begin{abstract}
Created by Hergé in 1929, Tintin is a truly successful publication, since these comic books have been translated into about a hundred languages and published throughout the world during the 20th century. Several studies have already been conducted on Tintin. However, the place and role of physical and sports activities practiced by this tireless journalist in the promotion of these highly sustainable activities have never been analyzed. Through both quantitative and qualitative analyses (descriptions, counts, frequencies and percentages), this work studies all the panels of the 23 albums of Tintin's adventures dealing with any form of physical exercise or sport. The results indicate that the representation of physical and sporting activity in Tintin's adventures remains steady and consistent from the first (1931) to the last book (1976). Thus, Hergé had never ceased to believe in the beneficial, physiological, psychological, moral and social effects of physical activity on his young, tireless hero. To summarize, the eternally youthful and perfectly fit, Tintin leads both his core band and occasional characters and may serve as a role model influencing young 20th century readers toward the benefits of an active lifestyle.
\end{abstract}

Keywords: comic book; Tintin; health; sport; neoteny

\section{Introduction}

The idea of understanding several aspects of society and culture by exploring Tintin, one of the most well-known fictional characters of Europe in the 20th century, is not entirely unprecedented. Several other comic characters have also been studied, albeit sporadically, with reference to their relationship with sport. In the UK, steeped in the comic book culture [1], Jeffrey Hill has published three very detailed studies about Alf Tupper [2-4]. In the same vein, John Bale has taken up the challenge of comparing the resistances and the excesses in Alf Tupper and Wilson of the Wizard in a chapter entitled "Fictions of Resistance: Alf Tupper and Wilson" in his book about running races [5]. Recently, further accentuating the scientific focus on competitive physical practices, Bale has treated this comparative study in greater depth in Sport and Leisure Histories, showing that both Wilson and Tupper embody athletes who worked to excess, who were obsessed with winning, and who, in this way, participated in the twentieth century's cult of speed [6].

In France, another country with a rich comic book tradition, scientific research on the links between sport and graphic narratives has been increasing since 2000, as is the case with studies on the Olympic Games in The Adventures of Asterix, or the Smurfs [7] and, 
more generally, on institutionalized and codified sports in comic books. Other articles have studied political mythologies in Pellos's comics, analyzing an athlete's fate when he goes off to war [8]. Another study of the albums of the comics series Michel Vaillant published in the 1960s uses different tools, drawn from fields such as historical study, management and philosophy, to highlight the myth of the progress of man [9]. This type of scientific approach has been extended also to films and television series, with studies such as, for example, one on the dermatological features of the "villains" of classical cinematography [10], or on the rates, types and frequencies of mortality and survival in the series "Game of Thrones" [11]. However, these French studies dedicated to sports in comic books rarely focus on the health and sanitary benefits of physical activities.

With regard to Tintin, however, several scientific papers have been published on a range of aspects, notably studies on the health of Tintin and his friends [12], the health of the famous reporter in relation to his travels and activity $[13,14]$ or the concept of stigma towards the mental illnesses that crop up in the albums [15].

One stone that has been left unturned and which we believe has significant relevance within the sociocultural context in which The Adventures of Tintin were created, is the role of the physical and sporting activities carried out by the tireless reporter should be put in relation with his eternal youth and health condition.

Thus, this is one of the key starting points of this study since through this compilation we intend (1) to demonstrate that there is a tradition-although it is not universally recognized-of the use of popular culture, expressed in this case for the creation, reading and dissemination of popular comics, to carry out and publish scientific studies about their significance; (2) that as a consequence of this analysis, it may be of interest to recover the "hygienic" tradition of physical "amateur" outdoor activities, even taking into account some of the most recent recommendations regarding the airborne transmission of the SARS-2 COVID coronavirus in the practice of physical activity [16], as has already been carried out with the vindication de facto of S XX school architecture carried out under basic hygienist ideas, with natural or forced ventilation, wide spaces and few students in each classroom and (3) some of the studies carried out previously in this vein, highlight mostly the negative characteristics (e.g., stigma) while it is relevant to highlight the positive ones too, as Tintin should be a possible model of physical activity and healthy life for the time being.

\subsection{The Life of Hergé and the Beginnings of Tintin}

Upon taking a look at the biography of Georges Prosper Remi (hereinafter Hergé, coined from the French pronunciation of his reversed initials: R.G.) [17,18], it becomes clear that his affinity for organized sport-or even physical exercise-was nonexistent, both from the sidelines and on the pitch, whereas his personal relationship with physical activity was much more consolidated, having begun early, and lasted throughout his lifetime.

Hergé (22 May 1907-3 March 1983) was born in the Belgian neighborhood of Etterbeek, into a lower-middle-class family. He began to draw cartoons in his class notebook at the age of eleven, around the same time he joined the Boy Scout brigade of Saint-Boniface School, before later becoming a member of the Boy Scouts. As a scout, he traveled quite a lot during the summer, visiting different European countries including Italy, Spain, Switzerland or Austria, camping and trekking through mountains, e.g., the $180 \mathrm{~km}$ hike across the Pyrenees in 1923. This example of physical activity reveals to us that Hergé was a person of action from an early age.

The Scouts' philosophy, based on the ideas of Sir Baden Powell [19], had a profound lifelong effect on Hergé, from his fondness for camping and the outdoors, to the values he upheld, such as personal loyalty and the importance of fulfilling commitments. Unsurprisingly, his favorite books during this time were Roughing It by Mark Twain; Three Men in a Boat by Jerome K. Jerome and The Three Musketeers by Alexandre Dumas [18].

Thus, the concept of natural outdoor physical activity [20] was prevalent throughout the life of Tintin's creator, from youth to adulthood, and this was reflected in the behavior 
of Tintin himself, which occurs almost always in natural contexts. This suggests an active, healthy lifestyle that is related to that of the Boys Scouts themselves established by BadenPowell [19]. Furthermore, one of his scout masters, Rene Weverbergh, was the person who initially encouraged him to pursue his love of illustration and who first published one of his drawings in the Saint-Boniface Scouts magazine Jamais Assez (Never Enough) and later in Le Boy Scout Belge. In 1926, Hergé drew a series for the same magazine titled Les Aventures de Totor, which centered around a Scouts patrol leader, making a transition from writing text below the drawing to including it in text bubbles. The series was published sporadically up until 1929. He also published work in other press around this time, such as Le Blé qui Lève, although he was unable to focus exclusively on drawing and found himself working in the Vingtième Siècle newspaper subscriptions department.

During the time of his work at this journal, influenced by the American burlesque cinema [21], he had direct knowledge of the comic strips drawn by the Americans George MacManus and Rudolph Dirks, which already anticipated the concept of the "clear line", and were sent to him by the newspaper's envoy in Mexico to follow the "Cristeros" war, Léon Degrelle [17].

Hergé's only known drawing of a formal and regulated sport was published in 1931, when Totor goes to watch a football match and ends up playing. This was the first and only time that Hergé would draw any of his main characters taking part in any regulated sport, Tintin included.

Insofar as the evolution of his characters is concerned-despite there being a distinct continuity from his earlier characters, such as Totor, to his final drawings of Tintin-Hergé often alleged that he had been inspired by his brother Paul's features. Other authors [22] argue that the real model of Tintin was the journalist, actor and traveler, Palle Huld, who became famous by winning the prize "Phileas Fogg" given by the Belgian journal Politiken, precisely for those activities (judging by the few photographs conserved, there is a real similarity, including some aspects of the dressing, such as the golf pants, the cap and the leggings) [23]. Nevertheless, he also said that "The idea for the character of Tintin and the sort of adventures that would befall him came to me, I believe, in five minutes, the moment I first made a sketch of the figure of this hero: that is to say, he had not haunted my youth nor even my dreams. "Although it's possible that as a child I imagined myself in the role of a sort of Tintin" [17].

Associated with the character's design, it should be noted that Hergé's brother, Paul Remi, shares with Tintin and the reporter Palle Huld some facial features that are defined as neotenic [24,25], in other words, childlike, and retaining the juvenile stages of evolution in the adult. Gould surmised that these childlike features are more likely to trigger protective attitudes and emotions in those in the company of the neotenic figure, almost as though he was a child in need of being looked after [24]. However, are Tintin's characteristic neotenic traits related to the physical activities he practices? Influenced by scouting and traveling, did Hergé build an active hero with a dynamic lifestyle that kept him young?

\subsection{Aims and Topic of This Study}

Accordingly, the aim of this study is to conduct a quantitative and qualitative analysis of the depictions of physical activity and sport in connection with healthy lifestyle in The Adventures of Tintin, illustrated by Hergé, contextualizing them in relation to the historical and cultural framework. In addition, we will try to connect the results with the neotenic concept of "always young", and with Hergé's psychological needs with respect to the changes that modernity brings against tradition, as a symbol of order and bourgeois stability.

\section{Materials and Methods}

\subsection{Sample and Procedures}

We analyzed the 23 published comic albums of The Adventures of Tintin. The first nine were published in black and white, and later in color (except for the first, Tintin in the Land 
of the Soviets), and then from 1942 onward, following the publication of The Shooting Star, the rest were always published in color.

We analyzed all of the illustrations in each one of the albums that depicted some form of exercise, physical activity or sport in order to cross-check the type of activity, the context surrounding it and the consequences for health it could produce. In addition to counting the number of times the action appeared, we assigned a percentage.

\subsection{Data Analysis}

We conducted a descriptive analysis of the activities under study by means of a count, indicating the frequency and percentages for each physical and sportive activity, with respect to health conditions, in a diachronic way.

To make the decision about the data collection methodology and its analysis (taking into account that it is an unusual type of observation), a focus group was formed [25] with two groups of co-authors, with a an expert person from the Research Group on Physical Activity and Sport (GICAFE) of the UIB (University of the Balearic Islands), another expert person from the Faculty of Sports Sciences of the University of Murcia and the presence of our beloved and respected Jaume Cruz, who was a world figure in the field of Sports Psychology, who developed, together with Ronald Smith (U. of Washington, USA) a systematic behavioral observation of athletes and coaches (Coach Behavioral Assessment System, CBAS).

The criteria that were decided on and applied to this study' methodology were the following: (1) avoid inferences about motivations, reasons, etc., and stick to what is drawn and expressed in each vignette (regarding the conceptual definitions of activity made up in the Introduction); (2) to select the vignettes, pay attention only to the difference between the activity carried out and the other activities of Tintin in the rest of the album (covering all the Tintin albums); (3) carry out a solely descriptive methodology of the findings (avoiding complex statistical elaborations that are not conceptually sustainable) and (4) if possible, contrast the results with others coming from the scarce scientific publications on Tintin with some of the topics analyzed in our study.

\section{Results}

Table 1 shows the frequency of the sports and physical activities depicted in the 23 Tintin albums, presented in both number and percentage form. The analysis shows that the most frequent activity includes races and chases, almost the same amount as all types of urban and countryside walks. There is a significant leap (a third less) to the next category of fights, then the following that encompasses rock climbing and mountaineering (including caving, which appears once in Explorers on the Moon). The frequency of navigation in all sorts of boats and rafts is almost the same, as is climbing. Swimming and driving vehicles (including the two times he drives tanks, once on Explorers on the Moon) are on a par with the "rescue and lifesaving" of his friends, which reminds us of his attachment to altruism and scouting values, as well as jumping and dancing.

Figure 1 gives an indication of the evolution and frequency of physical and sports activity over time, from 1931 (first album studied) to 1976 (last Tintin album published), outlining the different activities of each category and the number of pages where the illustrations appear (Figure 2). The range of activities (physical activities plus sports activities) goes from a minimum of 14 to a maximum of 23, with an average of 17.23 and a standard deviation of 2.56; and the number of pages dedicated to the same topic goes from a minimum of 12 to a maximum of 46 , with an average of 18.91 , and a standard deviation of 5.25. These data, without any significant differences statistically found, indicate that the depiction of physical and sports activity in The Adventures of Tintin remains stable and consistent from the first album to the last, covering a time period of 45 years. In view of such an observation, we can thus think that Hergé never ceased to believe in the beneficial effects, physiological, psychological, moral and social, of the physical activity of his young and tireless hero. 
Table 1. Frequency of the physical and/or sports activities in the 23 Tintin albums (total $N=479$ ).

\begin{tabular}{|c|c|c|}
\hline Physical and/or Sports Activity & $N$ & $\%$ \\
\hline Races and chases (running, cross-country, wheelchair) & 110 & 23.4 \\
\hline Walks, trekking, orienteering & 97 & 20.2 \\
\hline Fights (punches, sword, sticks) & 38 & 8.1 \\
\hline Rock climbing, mountaineering, caving & 36 & 7.6 \\
\hline Navigation in boats (sailboat, rowboat, motorboat), rafts & 33 & 7.0 \\
\hline Climbing (trees, chains, ropes, steps) & 27 & 5.7 \\
\hline Flying in a small plane, helicopter and rocket & 22 & 4.7 \\
\hline Swimming (rivers, lakes, sea) & 13 & 2.8 \\
\hline Rescue, lifesaving, assistance & 12 & 2.5 \\
\hline Motorsport (car, truck, tank) & 11 & 2.3 \\
\hline Jumps (walls, train, windows) & 11 & 2.3 \\
\hline Dancing & 10 & 2.1 \\
\hline Camping & 9 & 1.9 \\
\hline Horse riding & 9 & 1.9 \\
\hline Snorkeling and diving & 8 & 1.7 \\
\hline Riding other animals (camel, cow, bull) & 7 & 1.5 \\
\hline Motorcycling & 5 & 1.1 \\
\hline Parachuting & 4 & 0.8 \\
\hline Hunting & 3 & 0.6 \\
\hline Chess & 2 & 0.4 \\
\hline Cycling & 2 & 0.4 \\
\hline Exercise & 2 & 0.4 \\
\hline Crawling & 2 & 0.4 \\
\hline Cable car across a river & 1 & 0.2 \\
\hline Tightrope walking & 1 & 0.2 \\
\hline Weightlifting & 1 & 0.2 \\
\hline Zero-gravity movements & 1 & 0.2 \\
\hline Relaxation & 1 & 0.2 \\
\hline Skipping & 1 & 0.2 \\
\hline Total & 470 & 100 \\
\hline
\end{tabular}

Table 2 shows the health problems derived from and/or associated with the physical or sports activity of Tintin. It brings us back to the heart of the neotenic issue. Indeed, the young reporter's physical exercise practices cannot be dissociated from the disadvantages generated by his dizzying and tireless mobility. If staying young is about looking to the future and staying in motion, the negative effects of such an obsession must be addressed. According to the data, all of the health problems lead to a loss of consciousness, and in $90 \%$ of cases they were caused by a blow during a fight. Two health problems are linked to car accidents, two instances of heat exhaustion are caused by walking through the desert and there are four incidents of loss of consciousness due to the forces of gravity associated with acceleration during the take-off or landing of a lunar rocket. On a final note, there are two instances of fainting during mountaineering, one caused by falling down a crevice and another by an avalanche, as well as another due to a lack of oxygen in a near drowning incident when Tintin was swimming in a river. 


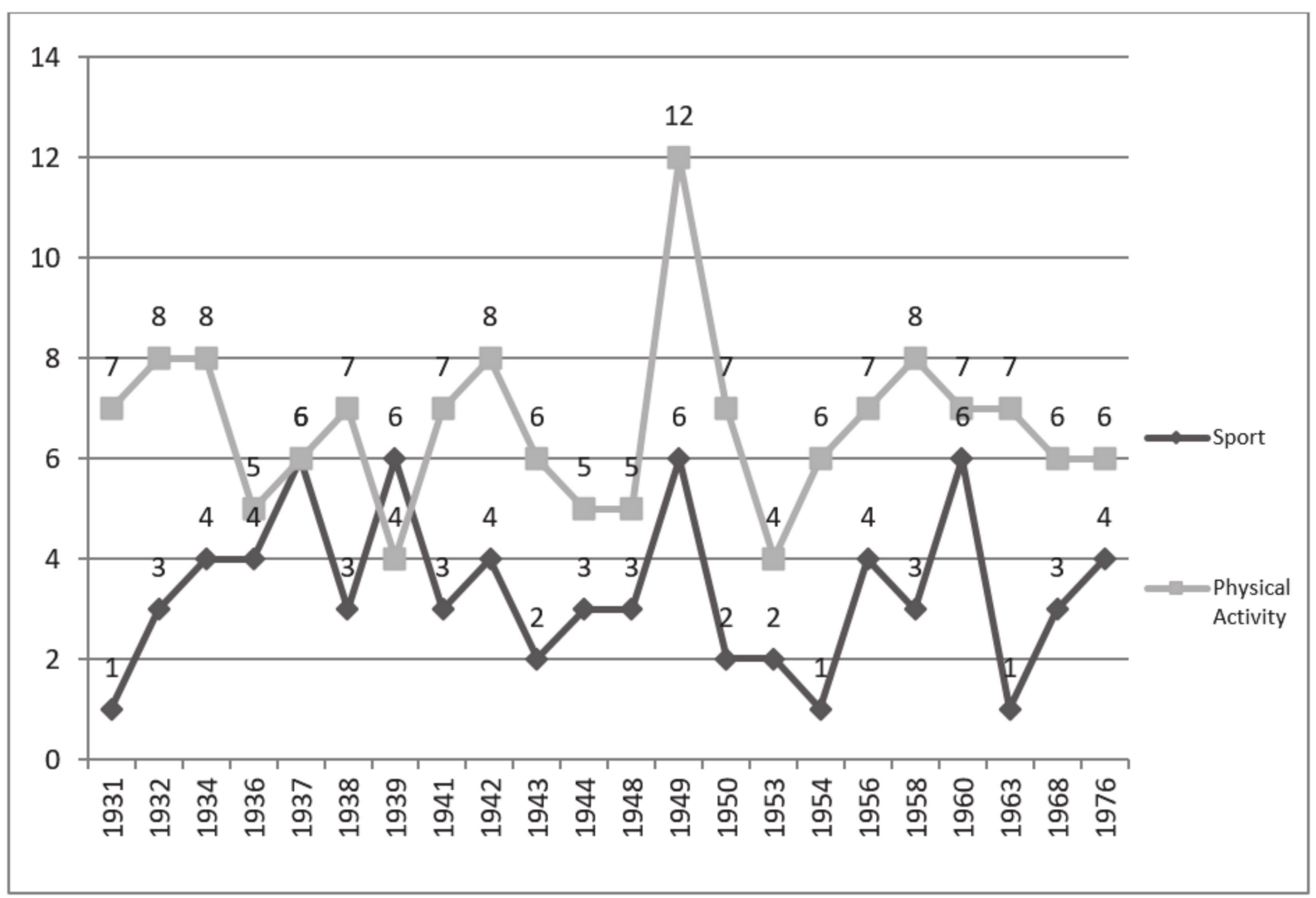

Figure 1. Distribution over time (1931-1976) of the physical activity and sports actions depicted in The Adventures of Tintin.

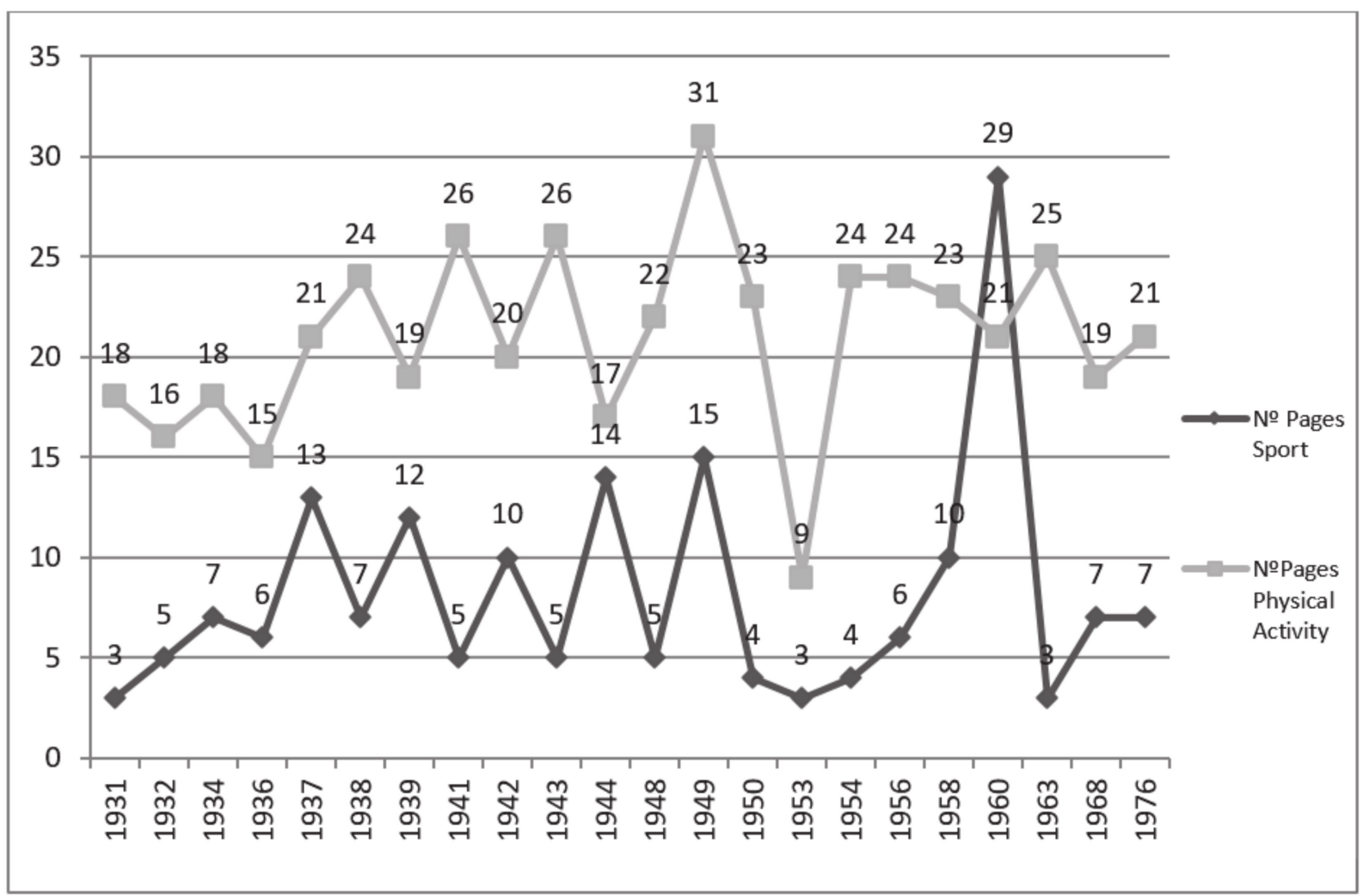

Figure 2. Distribution over time (1931-1976) of the number of pages showing physical activity and sports depicted in The Adventures of Tintin. 
Table 2. List of physical activities performed by Tintin with associated health problems.

\begin{tabular}{|c|c|c|c|}
\hline Album (Abbreviated) & Incident & Activity & Health Problem* \\
\hline Congo & Struck with a stick & Fight & Grade 4 concussion \\
\hline \multirow{2}{*}{ America } & Struck with a stick & Fight & Grade 4 concussion \\
\hline & Car accident & Car racing & Grade 4 concussion \\
\hline Pharaoh & Near-drowning (2) & Swimming & Nontraumatic L/C \\
\hline Broken Ear & Struck with a bar & Fight & Grade 4 concussion \\
\hline Black Island & Struck with a bar & Fight & Grade 4 concussion \\
\hline \multirow{3}{*}{ Ottokar's Sceptre } & Car accident $* *$ & Car racing & Grade 4 concussion \\
\hline & Struck with a rope & Fight & Grade 3 concussion \\
\hline & Struck with a stick & Fight & Grade 4 concussion \\
\hline \multirow{3}{*}{ Golden Claws } & Struck with a bar & Fight & Grade 4 concussion \\
\hline & Struck with a bottle & Fight & Grade 4 concussion \\
\hline & Heat exhaustion & Walk & Nontraumatic L/C \\
\hline \multirow{2}{*}{ Black Gold } & Heat exhaustion & Walk & Nontraumatic L/C \\
\hline & Struck with a stick & Fight & Grade 4 concussion \\
\hline Destination Moon & Rocket take-off & Flying & Nontraumatic L/C \\
\hline \multirow{4}{*}{ Explorers } & Rocket landing & Flying & Nontraumatic L/C \\
\hline & Rocket take-off & Flying & Nontraumatic L/C \\
\hline & Struck with a stick & Fight & Grade 4 concussion \\
\hline & Rocket landing & Flying & Nontraumatic L/C \\
\hline Calculus & Struck with a stick & Fight & Grade 4 concussion \\
\hline \multirow{2}{*}{ Tibet } & Fall down a crevice & Mountaineering & Grade 4 concussion \\
\hline & Avalanche & Rock climbing & Grade 4 concussion \\
\hline
\end{tabular}

Nontraumatic L/C: nontraumatic loss of consciousness; ${ }^{*}$ health problems obtained from Caume et al., 2015; ** Tintin was not driving.

\section{Discussion}

\subsection{What Physical and Sports Activity?}

After a brief analysis, it is clear that none of the adventures depict any regulated sport as such, nor does Tintin practice any; and there is only one incident (going to a football match) in The Adventures of Totor illustrated by Hergé before Tintin was created. As seen, most of the physical activities that Tintin performs occur in nature. Highlighting running, hiking, trekking, orientation and cross-country running represent $66.36 \%$ of total activities. This fact may be related to Tintin's-and Hergé's in real-life-heavy predilection for natural surroundings when practicing physical activity, in contrast with the "artificiality" of the settings used for regulated sports, such as a football stadium. However, it could also be understood as an "emancipation" - within the framework of a critical perspective of sport through drawings and comics—of its extreme regulation and a form of escaping, for example, the ubiquitous and almighty football [26].

Thus, this study focuses on natural physical activity, although certain cases in particularparachuting, mountaineering — could be classified as sports [27], despite there being no signs of competition or rules during their practice. In this regard, Tintin's activity matches that of a nonsedentary person who practices a significant amount and variety of physical activity yet is not compelled to take part in any regulated sport, either as a player or as a spectator. This preference for physical activity in the natural environment is based on the Hippocratic medical tradition and the principle of natura medicatrix from Greek antiquity. Taken up by German and Austrian empiricists of the 19th century [28], natura medicatrix proved to be a vital, physiological force that ensured the proper functioning of the human 
body and fought against deadly substances. Water, air, land and sun are sources of life through an established correspondence between the natural environment and the body. Based on this natural hygienic theory $[29,30]$, we can think that by systematically moving at the heart of the natural elements, Tintin contributes to ensuring his perpetual naturist therapy and to preserving his eternal youth.

\subsection{Quantity and Quality of Physical Activity and Sport}

Firstly, upon analyzing the evolution of physical and sports activity in the albums throughout the years, it is important to highlight that it remains relatively stable, both in terms of quantity and type, from the first album, drawn in 1931, until the last, created in 1976, regardless of the enormous difference in scenarios, places, eras and plots around which the adventures were developed. This is also corroborated by the high consistency of the number of actions and illustrated pages throughout these 45 years.

This aspect is clearly aligned with the core ideas for the character: the maintenance of Tintin's youth [31] and his continuous practice of physical activity in preferably natural areas.

Insofar as the type of physical activity is concerned, it is worth pointing out that, based reliably on the adventurous and heroic traits of Tintin, the fights and struggles pop up over the course of his adventures, but never from a "superhero" perspective (unlike other illustrated characters who embark on adventures), but rather as someone who loses fights, takes blows from, and at times wins battles against his adversaries. Along these lines, this helps normalize the character and set him apart from many other illustrated heroes who possess more power and strength in clashes with their enemies and adversaries.

The physical and sporting activities practiced by Tintin during his adventures are extremely frequent (479 pictorial evocations) and varied (no less than 40 different practices have been recorded in Hergé's work). It should be noted that the category of sports using devices (water, air and land) is remarkably present. Indeed, when all aquatic activities (rowing, rafting, outboard races, skipping, etc.), aerial activities (parachuting, aviation, helicopter flying, etc.) and road activities (cycling, motorcycling, car racing, etc.) are combined, they are present 78 times in the 23 albums studied $(16.2 \%)$. The frequency of this category of mechanical activities approaches that of natural hygienic practices (110 out of 479 or $23.4 \%$ ) and that of walking and trekking (97 out of 479 or $20.2 \%$ ).

While Hergé, as an innovator, drew the adventures of his young hero at a pivotal time that was still lagging behind in making speed accessible to all [32], it must be noted that Tintin was, for his part, immersed by his creator in "high-speed landscapes" built between the two world wars. As proof, in The Blue Lotus (1934), Hergé is fascinated by Sir Malcolm Campbell's world record in the car Blue Bird at $276.82 \mathrm{mph}$.

\subsection{Neoteny and Physical Activity}

The fact that the level and type of physical activity remains stable over the 50 years and 23 adventures can also be associated with an aspect that has been highlighted by all Tintin critics: his unchangeable youthful appearance. This aspect of Tintin is well known to experts in evolutionary biology, since the phenomenon of neoteny (i.e., the retention of juvenile facial features in adult species) [33] seems to be linked to the search for safety that can be provided from both the parents and the society in which they are immersed [24].

The everlasting youthfulness of the character (Tintin, as mentioned before, did not bear a physical resemblance to Hergé himself but instead with his brother) [14], in addition to the above-mentioned concept of phenotypic evolution, correlates with the fact that his creator remained active like a boy scout throughout his whole life, staying connected to the outdoors almost until he died. Thus, this would establish a relationship between the life of Hergé, his thoughts on the need for physical exercise and its integration into people's everyday life. 


\subsection{Physical Activity and Health}

It is particularly relevant to point out that, although in all Tintin's adventures there are regular incidents of health problems such as insomnia, anxiety, various hospital admissions and two surgical procedures $[10,19]$, very few of them are directly linked to physical or sports activity, given that, aside from the fights and car accidents, only three incidents take place that could be considered associated with or caused directly by Tintin's physical activity: two during mountaineering and one whilst swimming. It can be assumed that from Hergé's point of view, and in a manner consistent with the above analysis, practicing physical activity does not lead to negative consequences but instead can be associated with the preservation of people's health and their juvenile appearance, portrayed directly in the behavioral pattern of Tintin. In the same vein, and except for the odd instance involving walking through the desert under the sun, without shade and water, Tintin shows almost no signs of fatigue, which is even more significant considering his most repeated physical activity is running. Similarly, although perhaps with broader theoretical scope, Tintin rarely gets sick, apart from suffering from a common cold [10], nor does he have any infections or health problems derived from a sudden illness.

In light of the facts available regarding the socio-medical culture at the turn of the 20th century, dare we say there is an indication that The Adventures of Tintin are embedded in the Natural Hygiene Movement-which would nowadays be tied to the concept of quality of life- that materialized toward the end of the 19th century and would be characterized by widespread concern for public health, for research on and the explanation of the source and the mechanisms of endemic and epidemic diseases, as well as for the application of principles associated with those attributes currently known as "quality of life" [30]. This movement was almost entirely environmental at first (which involved cleanliness, hygiene, light, sun and access to "clean" nature), and later became-thanks to the microbiological breakthroughs toward the end of the century-a combination of both factors. In a context of economic crisis, the political rise of extremes in Europe [34] and the sharp demographic decline between 1870 and 1945 for France and, to a lesser extent, for Belgium [35], it is easy to understand that the alarmist medical discourse contributes to forging major social fears. Physical activity therefore serves a political project of "repopulate", health promotion within the context of "urban hygiene", "child hygiene and school sanitation" and "industrial hygiene", as shown in the communications and conferences of the Hygiene and Demography movement [30]. Moreover, Hébert's Natural Method [36] and the French naturist perspective reached many countries, including Belgium [37]—Hergé's countryin the early 1920s, and were incorporated into the development of a new approach to therapeutic treatments to preserve patient well-being. A former Scout, Hergé is probably not insensitive to this natural outdoor gymnastics.

That said, natural hygiene took a eugenic turn [38] in the first third of the 20th century as a result of impactful theories about inheritance, notably the Lamarckian hypothesis regarding the transmission of acquired characteristics. It should be noted that this conceptconsidered somewhat "taboo" in the scientific field of physical activity and sports-is resurfacing on the basis of various findings about epigenesis in animals and the impact of physical activity carried out by ancestors on their successive generations [39], although the debate concerning its true evolutionary meaning has not yet been generalized.

Lastly, social hygiene to a certain extent became a "people's technology"; "it concerns normative sociology: we regard man as an industrial material or, rather, as an animal machine. The hygienist is thus the engineer of the human machine" [29]. This trend would not take long in becoming aligned with extremist views such as the racist and eugenic ideas that proliferated in the early to mid-twentieth century.

There have been previous studies on the presence of prejudices and stigmatizing ideas regarding mental health in The Adventures of Tintin [15]. These approaches evolve as the albums become more modern, but it should be remembered that natural hygiene linked the maintenance of hygiene (both from an environmental and biological perspective) to the mental stability in people [30]. This function to disseminate ideas and attitudes through 
comics has also been studied in relation to the introduction of a positive and nonhumorous vision of the Olympic Games and the sports practiced therein by means of the Asterix comics, for example [7].

\section{Conclusions}

Taking into account the overall analysis of the physical and sports activity of Tintin, we can confirm that (1) The Adventures of Tintin are anchored in a sociocultural context in which natural physical activity, which is part of the ancestral principle of natura medicatrix, is regarded as an complement to daily active life; (2) no negative effects to practicing physical activity appear, either in the form of injuries or fatigue; (3) alongside other comics in different settings around the world, Tintin has helped demonstrate the benefits of an active lifestyle to readers for a significant part of the 20th century and (4) despite the natural hygiene traditional framework in which the hero's bodily practices take shape, as well as any problem deriving from the Belgian political position on its colonies, The Adventures of Tintin are never criticized even under current benchmarks. They could be considered a positive model of active life. However, it is worth highlighting the complexity of the famous reporter, who is careful not to throw himself into some kind of modernity that is a source of instability and seduces him, as evidenced by his hyperactivity, his frantic quest for travel and his taste for motorized activities.

In the end, we would be inclined to think that by putting oneself in the action continuously and by devoting oneself as often as possible to physical activities, Tintin thus finds his fountain of youth, the one that guarantees his unlimited youth. In 2019, Hergé's hero was 90 years old but his youth is undeniable! Anyway, if Tintin continues to fascinate his readers, would it not be simply because, in the light of his adventures, he questions, in a recurrent and subtle way, the notion of mobility on the scale of the person, a nation or even a civilization and, with it, the future of the world?

In sum, we can say that The Adventures of Tintin have already been analyzed with respect to the health of the hero or the stigma toward mental illness in medical journals, such as the American Journal of Neuroradiology, the British Medical Journal or La Presse Medicale [13-15,39]. In fact, Hergè was a person of action from his youth and describes the physical activities of his hero as a complement to an active lifestyle, as outlined in this article, that brings significant benefits—physiological, psychological, moral and socialthat can be the source of Tintin's eternal youth. In future studies, it would be interesting to analyze the potential impact of the ideas and attitudes about the practice of physical activities in natural environments, disseminated through The Adventures of Tintin, in the promotion of an active lifestyle in his readers.

Author Contributions: Conceptualization, A.G.-M., A.O., S.L.-C., J.C. and C.V.; methodology, A.G.-M., A.O. and C.V.; data curation and analysis, A.G.-M., S.L.-C. and C.V.; writing-original draft, A.G.-M., A.O., S.L.-C., J.C. and C.V.; writing, review and editing, A.G.-M., A.O., S.L.-C., J.C., Y.D. and C.V. All authors have read and agreed to the published version of the manuscript.

Funding: This research received funding from the program "Posam Valors" ("Values in Sport"), Illes Balears regional Government, Spain (Ref.: CAIB, CE-2-2018).

Institutional Review Board Statement: Not applicable.

Informed Consent Statement: Not applicable.

Data Availability Statement: The data presented in this study are available in this same article.

Acknowledgments: The authors would like to thank the children and their families who have read Tintin's albums for making this study possible.

Conflicts of Interest: The authors declare no conflict of interest. 


\section{References}

1. Khoury, G. True Brit: A Celebration of the Great Comic Book Artists of the UK; TwoMorrows Publishing: Raleigh, NC, USA, 2004.

2. Hill, J. 'I Like to Have a Go at the Swanks': Alf Tupper and English Society, 1945-1990. In Sport, Representation and Evolving Identities in Europe; Dine, P., Crosson, S., Eds.; Peter Lang: Oxford, UK, 2010; pp. 79-100.

3. Hill, J. 'I'll Run Him': Alf Tupper, Social Class and British Amateurism. Sport Hist. 2006, 26, 502-519. [CrossRef]

4. Hill, J. Alf Tupper-'The Tough of the Track' and the Class Struggle in British Athletics. In Sporting Lives; Dave, D., Ed.; Institute for Performance Research, Manchester Metropolitan University: Manchester, UK, 2011; pp. 30-39.

5. Bale, J. Running Cultures: Racing in Time and Space; Routledge: London, UK, 2004.

6. Bale, J. Asserting the Rural and the Truth about Wilson. In Sport and Leisure Histories; Dave, D., Ed.; Sport and Leisure History Cluster, Manchester Metropolitan University: Manchester, UK, 2013; pp. 183-198.

7. Laffage-Cosnier, S.; Vivier, C.; Thiébaut, M. Les Jeux olympiques célébrés par Bibi Fricotin, Les Pieds Nickelés, Astérix et Les Schtroumpfs (The Olympic Games celebrated by Bibi Fricotin, The Nickel-plated Feet, Asterix and The Smurfs). Eur. Stud. Sports Hist. 2014, 7, 197-221.

8. Laffage-Cosnier, S.; Loudcher, J.-F.; Vivier, C. La guerre et ses représentations dans la Bande Dessinée: La destinée du héros sportif chez Pellos dans le journal Junior (1938-1940) (War and its representations in the Comic Strip: The destiny of Pellos's sport hero in the Junior newspaper (1938-1940)). Mod. Contemp. Fr. 2012, 20, 287-305. [CrossRef]

9. Laffage-Cosnier, S.; García-Arjona, N.; Vivier, C. Engines at Top Speed! Using the Adventures of a Comic Book Motorsports Hero as an Approach to Understanding Recent French History. Sport Hist. 2018, 38, 1-22. [CrossRef]

10. Croley, J.A.; Reese, V.; Wagner, R.F. Dermatologic Features of Classic Movie Villains: The Face of Evil. JAMA Dermatol. 2017, 153, 559-564. [CrossRef] [PubMed]

11. Lystad, R.P.; Brown, B.T. "Death is certain, the time is not": Mortality and survival in Game of Thrones. Inj. Epidemiol 2018, 5, 44. [CrossRef] [PubMed]

12. Castillo, F. Tintín-Hergé: Una vida del Siglo XX; (Tintin-Hergé; A XX Century life); Fórcola, Colección Señales Nº 6: Madrid, Spain, 2011.

13. Caumes, E.; Epelboin, L.; Leturcq, F.; Kozarsky, P.; Clarke, P. Tintin's travel traumas: Health issues affected the intrepid globetrotter. Presse Med. 2015, 44, e203-e210. [CrossRef] [PubMed]

14. Chanson, P. Les aventures de Tintin chez le médecin (The adventures of Tintin visiting the doctor). Presse Med. 2015, 44, 584-585. [CrossRef] [PubMed]

15. Medrano, J.; Malo, P.; Uriarte, J.J.; López, A.P. Stigma and Prejudice in Tintin. Br. Med. J. 2009, 339, 1406-1407. [CrossRef] [PubMed]

16. Dominski, F.H.; Brandt, R. Do the benefits of exercise in indoor and outdoor environments during the COVID-19 pandemic outweigh the risks of infection? Sport Sci. Health 2020, 16, 583-588. [CrossRef] [PubMed]

17. Assouline, P. Hergé, the Man Who Created Tintin; Oxford University Press: New York, NY, USA, 2009.

18. Farr, M. The Adventures of Hergé, Creator of Tintin; Last Gasp: San Francisco, CA, USA, 2007.

19. Baden-Powell, R. Scouting for Boys: A Handbook for Instruction in Good Citizenship; Oxford University Press: New York, NY, USA, 2005.

20. Villaret, S. Naturisme et Education Corporelle. Des Projets Réformistes aux Prises en Compte Politiques et Educatives (XIXe-Milieu du XXe Siècles); (Naturism and body education. From reformist projects to political and educational considerations (19th-middle of the 20th century)); L'Harmattan, coll. Espaces et Temps du Sport: Paris, France, 2005.

21. Groensteen, T. La Bande Dessinée, Son Histoire et ses Maîtres; (The comic book, its history and its masters); Skira-Flammarion: Paris, France, 2009.

22. D'Ors, J.E. Tintin, Hergé y los Demás; (Tintin Hergé and the others); Plaza y Janés: Madrid, Spain, 1988.

23. Pictures of This Clothing Style Which Influenced Hergé Can Be Seen on the Website Tintinomania. Available online: https: / / tintinomania.com/tintin-pantalon-de-golf (accessed on 2 September 2020).

24. Gould, S.J. Ontogeny and Phylogeny; Belknap, Harvard University Press: Cambridge, MA, USA, 1977.

25. Edmunds, H. The Focus Group Research Handbook. In The Bottom Line; Emerald Group Publisher Limited: Bingley, UK, 1999; Volume 12. [CrossRef]

26. Laffage-Cosnier, S.; Vivier, C. Introduction: Quand le 99e Art se joue du sport (Introduction: When Graphic Narratives Criticise Sport). Comicalités 2018. [CrossRef]

27. Eichberg, H. Body Cultures: Essays on Sport, Space and Identity; Routledge: New York, NY, USA, 1998.

28. Rikli, A. Médecine Naturelle et Bains de Soleil (Natural medicine and sunbathing); Georges Bridel \& Cie: Lausanne, Switzerland, 1905.

29. Murard, L. L'haleine des faubourgs. Ville, habitat et santé au XIX siècle (The Breath of the Suburbs. City, Habitat and Health in the Nineteenth Century). Recherches 1977, 9, 1443.

30. Arteaga, L. Higienismo y ambientalismo en la medicina decimonónica (Hygienism and Environmentalism in the Nineteenthcentury Medicine). Dynamis Acta Hisp. Med. Hist. Illus. 1985, 5-6, 417-425.

31. Apostolidès, J.M. Hergé and the Myth of the Superchild. Yale Fr. Stud. 2007, 111, 45-57.

32. Studeny, C. L'invention de la Vitesse. France XVIII $-X X^{e}$ Siècle; (The invention of speed. France 18th-20th century); Gallimard: Paris, France, 1995. 
33. Mosse, G.L. The Nationalization of the Masses: Political Symbolism and Mass Movements in Germany from the Napoleonic Wars through the Third Reich; Howard Fertig: New York, NY, USA, 1975.

34. Hébette, F. L'évolution démographique de la Belgique (The demographic evolution of Belgium). Population 1954, 9, 85-194.

35. Delaplace, J.M. Georges Hébert, Sculpteur de Corps; (Georges Hébert sculptor of bodies); Vuibert: Paris, France, 2005.

36. Nascimento-Jubé, C.; Dalben, A. A mid Progress and Wilderness: Early Reception of Georges Hébert's Naturist Ideas in Brazil during the First Half of the Twentieth Century. Int. J. Hist. Sport 2017, 34, 1541-1562. [CrossRef]

37. Carol, A. Histoire de L'eugénisme en France. Les Médecins et la Procréation XIXe-XXe Siècles; (History of eugenics in France. Doctors and procreation in the 19th-20th centuries); Le Seuil: Paris, France, 1995.

38. Ntanasis-Stathopoulos, J.; Tzanninis, J.G.; Philippou, A.; Koutsilieris, M. Epigenetic regulation on gene expression induced by physical exercise. J. Musculoskelet Neuronal. Interact 2013, 13, 133-146.

39. Castillo, M. Tintin and Colleagues Go to the Doctor. Am. J. Neuroradiol. 2011, 32, 1975-1976. [CrossRef] [PubMed] 